\title{
CONFERÊNCIA ANUAL DA REAL SOCIEDADE DE GEOGRAFIA E DO INSTITUTO DOS GEÓGRAFOS BRITÂNICOS - 1997
}

\section{ALINA ESTEVES ${ }^{1}$}

Realizou-se no passado mês de Janeiro, entre os dias 7 e 10, mais uma Conferência Anual dos geógrafos britânicos cuja promoção e divulgação é feita pela Real Sociedade de Geografia e pelo Instituto dos Geógrafos Britânicos (Royal Geographical Society - Intitute of British Geographers).

Em 1997 a organização da Conferência foi da responsabilidade do Departamento de Geografia da Universidade de Exeter localizada no condado de Devon, que no seu vasto campus acolheu mais de 620 participantes vindos das mais diversas regiões do Reino Unido, da Europa continental (Alemanha, França, Hungria, Dinamarca, Grécia, Espanha, Portugal), EUA, Canadá, Austrália, Nova Zelândia, Hong Kong e ainda de alguns países africanos (Zâmbia, Tanzânia, Quénia), asiáticos (Paquistão, Índia, Indonésia e China) e sul-americanos (Brasil, Argentina, Chile) com quem a Grã-Bretanha mantém relações de cooperação nos domínios do desenvolvimento científico e técnico.

A Conferência de 1997 teve dois temas centrais, Regulação: processos, instituições e resultados e A Europa: culturas e ambientes. Estavam inscritas 435 comunicações cuja apresentação e discussão se dividiu por 21 Grupos de Investigação e de Estudo (Research Groups e Study Groups) num total de 53 sessões.

Decorreram ainda no âmbito desta Conferência reuniões, exposições, posters, palestras e debates coordenados pelos Grupos de Investigação e de Estudo integrados em várias redes internacionais de intercâmbio entre universidades e instituições ligadas ao planeamento.

Foram organizadas 4 visitas de estudo a áreas distintas do condado de Devon, cujo objectivo era conhecer os problemas e as possíveis soluções inerentes ao ordenamento e revitalização de espaços tão variados como as praias da Riviera inglesa, nomeadamente Torbay, o espaço urbano degradado da cidade de Plymouth, a geomorfologia e gestão do solo no Parque Nacional de Exmoor e o planeamento de áreas rurais tradicionais como a região de West Devon.

\footnotetext{
1 Assistente da Faculdade de Letras, Universidade de Lisboa. Investigadora do Centro de Estudos Geográficos. Centro de Estudos Geográficos, Faculdade de Letras, Cidade Universitária, 1699 LISBOA Codex. Tel: (351-1) 79402 18; fax: (351-1) 79386 90; e-mail: ceg@ mail.telepac.pt.
} 
Os trabalhos da Conferência desenrolam-se em sessões dos Grupos de Investigação (Research Groups - RG) e dos Grupos de Estudo (Study Groups - SG) que cobrem não apenas os campos do conhecimento geográfico mais consolidado, mas avançam também para áreas de estudo inovadoras.

De entre os aspectos mais tradicionais do saber geográfico, são de salientar as sessões do Grupo de Investigação da Geografia Económica onde se debateram os problemas da reestruturação económica e reconfigurações institucionais e espaciais a ela associadas, a flexibilidade cada vez mais importante para o sector dos serviços, a regulação social e a globalização da economia.

Um outro Grupo de Investigação com elevado número de participantes foi o da Geografia Social e Cultural que nas suas sessões abordou temas ligados ao turismo, nomeadamente a criação de novos espaços turísticos, os impactes das actividades turísticas nos espaços naturais, a sustentabilidade dos espaços já existentes e a criação de novas actividades de lazer e recreio.

O Grupo dos Estudos Geomorfológicos foi o que apresentou maior número de comunicações e posters, e os temas debatidos iam desde os impactes das alterações climáticas nos processo hidrológicos, à sedimentação nas bacias aluviais durante o Quaternário, passando pela importância dos lagos artificiais nas alterações da drenagem das bacias dos rios. Em colaboração com o Grupo do Ambiente, a sessão sobre poluição, ordenamento das áreas costeiras e gestão dos recursos hídricos tornou-se muito importante, pois permitiu o confronto de investigadores representando organismos e interesses tão diferentes como institutos ligados à gestão e distribuição da água, empresas de produção de pesticidas e herbicidas, organismos ligados à reciclagem de lixos e ao tratamento de efluentes urbanos.

O Grupo de Investigação da Geografia da População dividiu os seus trabalhos em dois temas principais: os movimentos internacionais de população e os seus impactes nos sistemas de segurança social e no mercado de habitação dos países de acolhimento, e o declínio da fertilidade nos países do Terceiro Mundo.

O Grupo de Investigação da Biogeografia promoveu uma longa, e muito concorrida, sessão de trabalho sobre a teoria da biogeografia, a biodiversidade em meios marginais e em áreas de floresta e a análise dos pólens.

Os transportes foram também estudados pelo respectivo Grupo de Investigação numa sessão que abordou do ponto de vista teórico e prático a regulamentação e privatização dos transportes, o impacte dos diversos modos de transporte no espaço e os comportamentos dos utentes segundo os meios de transporte utilizados. Mereceram especial destaque os transportes aéreos e ferroviários.

Dentro dos Grupos de Investigação e de Estudo com aspectos mais inovadores na investigação geográfica é de salientar o Grupo dos Métodos Quantitativos, onde os SIGs são utilizados como ferramenta nos estudos de impacte ambiental e na elaboração de modelos, e onde a análise fractal está a assumir uma importância crescente.

O Grupo de Investigação da Geografia Política promoveu uma vasta sessão sobre a unificação alemã onde se debateram as transformações económicas, 
sociais, urbanas e demográficas que se registaram após Outubro de 1990 na Alemanha e quais as perspectivas futuras que se vislumbram.

Ainda dentro dos aspectos mais inovadores da ciência geográfica, o Grupo de Estudo da Geografia do Género promoveu em colaboração com o Grupo da Biogeografia, uma sessão com o objectivo de analisar o papel da mulher na investigação em geografia física, abordando também casos de estudo da utilização diferenciada dos recursos biológicos segundo o género.

O Grupo da Geografia da Saúde abordou duas grandes temáticas. Por um lado, as alterações ambientais no planeta e os riscos para a saúde das populações, e por outro lado o funcionamento dos sistemas nacionais de saúde em vários países do mundo.

A ética da Geografia esteve também representada, não através de um grupo específico, mas de um conjunto de geógrafos preocupados em desenvolver ligações entre a Geografia e a Filosofia. Foram abordados temas como a ética profissional, a ética geográfica e o papel do geógrafo no desenvolvimento do mundo actual.

Em 1998 a Conferência Anual realizar-se-á na cidade inglesa de Guildford, 50 $\mathrm{km}$ a sul de Londres, e será da responsabilidade do Departamento de Geografia da Universidade de Kingston-upon-Thames. 